\title{
Morphological and Histochemical Changes in the Regenerating Vomeronasal Epithelium
}

\author{
Junko YOSHIDA-MATSUOKA ${ }^{1,2) *}$, Masato MATSUOKA ${ }^{3)}$, Richard M. COSTANZO ${ }^{4)}$ and Masumi ICHIKAWA ${ }^{1,2)}$ \\ ${ }^{1)}$ Department of Developmental Morphology, Tokyo Metropolitan Institute for Neuroscience, Fuchu, Tokyo 183-8526, ${ }^{2)}$ CREST of the \\ Japan Science and Technology Corporation, Kawaguchi, Saitama 332-0012, ${ }^{3)}$ Department of Neurobiology and Anatomy, Niigata \\ University School of Medicine, Niigata, Niigata 951-8510, Japan and ${ }^{4)}$ Department of Physiology, Virginia Commonwealth University, \\ Medical College of Virginia Campus, Richmond, Virginia 23298-0551, U.S.A.
}

(Received 20 June 2000/Accepted 12 August 2000)

\begin{abstract}
Receptor cell degeneration and regeneration within the vomeronasal organ (VNO) of the rat was studied using both electron microscopy and histochemical methods. Electron microscopy was employed to examine the morphological changes along the surface of the sensory epithelium, and histochemical markers were used to monitor the changes in the epithelial cell layers. Transection of the vomeronasal nerves induced selective degeneration of the receptor cells, and within six days, a significant decrease in the number of receptor cells was observed. During the subsequent stage of receptor cell regeneration, cilia and bud-like structures characteristic of a developing sensory epithelium were seen. By day 15 , thin microvilli covering the surface of the receptor cells reappeared in the sensory epithelium. The neural cell adhesion molecule (NCAM) and two vomeronasal system-specific lectins; 1) Bandeiraea simplicifolia lectin (BSL-I) and 2) Vicia villosa agglutinin (VVA) were used as the histochemical markers. NCAM immunoreactivity on the surface of the epithelium was observed to be decreased significantly six days after nerve transection, and was restored during receptor cell regeneration (day 15). The reactivity of the two lectins, BSL-I and VVA, was decreased slightly during degeneration, but was still detectable at the time of maximum receptor cell degeneration (day 6). Lectin reactivity was restored to control levels by day 15 . These findings suggest that (1) NCAM is a useful marker for vomeronasal receptor cells and that the vomeronasal system-specific lectins may bind to both receptor and supporting cells and (2) degeneration of vomeronasal receptor cells occurs during the first week (day 6) following nerve transection and the receptor cell population begins to recover within 15 days. The morphological changes observed during receptor cell regeneration suggest that the stages of VNO receptor cell regeneration are similar to those observed during development.
\end{abstract}

KEY WORDS: degeneration, rat, regeneration, vomeronasal organ.

J. Vet. Med. Sci. 62(12): 1253-1261, 2000

Two chemosensory systems (the olfactory and vomeronasal) play an important role in the detection and processing of chemical signals in mammals. Most vapor-phase chemicals in the environment are detected by olfactory receptor cells. Some chemical signals, such as pheromones related to reproductive behavior, are detected by vomeronasal receptor cells. The olfactory organ is located in the caudal part of the nasal cavity. Olfactory receptor cells are located in the sensory epithelium lining the upper regions of the nasal cavity. These receptor cells are bipolar neurons. Their apical dendrites are covered with cilia that extend into the nasal cavity where they come in contact with odor molecules. The vomeronasal organ is a tube-like structure located at the base of the nasal cavity. It has a central lumen lined with a sensory epithelium on its medial side and a nonsensory epithelium on its lateral side. The vomeronasal glands are located on the lateral side adjacent to the nonsensory epithelium and secrete substances that assist in vomeronasal organ function. The vomeronasal receptor cells occupy about $3 / 4$ of the sensory epithelium and similar to the olfactory receptors, are bipolar neurons. At the surface of the epithelium, the vomeronasal receptor cells are covered with microvilli that extend into the lumen. Axons from both olfactory and vomeronasal receptor cells pass

\footnotetext{
* Correspondence to: Yoshida-Matsuoka, J., Department of Developmental Morphology, Tokyo Metropolitan Institute for Neuroscience, 2-6 Musashidai, Fuchu, Tokyo 183-8526, Japan.
}

through the cribriform plate and project to different regions of the olfactory bulb. Axons from the olfactory receptor cells terminate in the main olfactory bulb (MOB) and those from the vomeronasal receptor cells project to the accessory olfactory bulb (AOB).

In both the olfactory and vomeronasal systems, receptor cells have the capacity to produce new cells continuously. Several morphological studies have described the regeneration of receptor cells in the olfactory epithelium following nerve transection or olfactory bulb removal $[7,8,18]$. Costanzo and Graziadei [5] studied the degeneration of receptor cells in the olfactory epithelium after nerve transection and found that the receptor cell number was decreased to a minimum at four days. After a recovery period of 30 days, the receptor number increased again, although the thickness of the epithelium did not increase. The newly regenerated receptor cells reestablished connections with the main olfactory bulb within 35 days. Such regeneration and functional recovery of olfactory receptors was observed in both young and old animals [19]. Yee and Costanzo [35] performed behavioral experiments following recovery from olfactory nerve transection in hamsters. They found that the ability to discriminate between chemical odorants was restored after a recovery period of 40 days. This indicates that there is functional recovery of receptor cells and reestablishment of their central connections. In the vomeronasal system continuous 
regeneration of receptor cells also occurs in both young and adult animals. When the vomeronasal nerve bundles are transected, or when the olfactory bulb is removed, vomeronasal receptor cells degenerate, immediately followed by receptor cell regeneration. This has been documented in rodents [2,3] and garter snakes [32,33]. Recently, in a quantitative study of the vomeronasal epithelium during degeneration and regeneration, Ichikawa et al. [13] showed that transection of the vomeronasal nerves resulted in the degeneration of $84 \%$ of the receptor cells, followed subsequently by complete restoration of the receptor cell population to control levels. The number of receptor cells decreased significantly during the first six days after nerve transection, and then increased to control levels over a period of 60 days.

Several studies examining the immunocytochemical changes during regeneration in the olfactory system have been reported $[9,22,24,26]$. However, in the vomeronasal system, only one study has been reported on the immunocytochemical changes in the epithelium following nerve transection. After AOB removal, Gi $\alpha$ and Goo expressing receptor cells were markedly reduced in number [14]. To investigate in further detail the changes during degeneration and regeneration in the vomeronasal system, we conducted both electron-microscopic and histochemical studies of the vomeronasal organ, using NCAM (neural cell adhesion molecule) and two specific lectins; 1) Bandeiraea simplicifolia lectin (BSL-I) which recognizes equally $\mathrm{N}$-acetylgalactosamine and D-galactose and 2) Vicia villosa agglutinin (VVA) which recognizes only $\mathrm{N}$-acetylgalactosamine. These two lectins have been shown to have a high affinity for the vomeronasal epithelium $[11,27,30,31]$. We report here that the reactivities for NCAM and the two lectins decreased in intensity after nerve transection and increased during the regeneration. These immunocytochemical and histochemical findings combined with the electron-microscopic observations provide new information on the stages of receptor cell regeneration in the vomeronasal organ and the accompanying morphological changes.

\section{MATERIALS AND METHODS}

Animals: Male Sprague-Dawley (SD) rats were housed in a temperature-controlled room under a $12 \mathrm{hr} / 12 \mathrm{hr}$ light/dark cycle. The animals were kept in acrylic cages with woodchip bedding and had unlimited access to the usual laboratory chow and water. All the experimental procedures employed were approved by the Institutional Animal Care Ethics Committee of the Tokyo Metropolitan Institute for Neuroscience.

Surgery: The rats were anesthetized with sodium pentobarbital $(20 \mathrm{mg} / \mathrm{Kg})$ prior to the surgery. Then, the frontal bone covering the left olfactory bulb was removed and a custom-made Teflon blade was used to cut both the vomeronasal and olfactory nerve fibers passing between the cribriform plate and the left olfactory bulb [5]. The vomeronasal and olfactory nerves on the right side were left intact and served as the control. Following the surgery, the animals were carefully monitored until they recovered from anesthesia, and were then returned to their home cages. The vomeronasal organs of the SD rats were examined at postoperative recovery times of 2, 6, 10, 15 and 42 days.

Electron-microscopic examination: Two animals for each of the five postoperative recovery times were selected for the electron-microscopic study. The animals $(n=10)$ were deeply anesthetized with pentobarbital and perfused with $0.9 \%$ saline followed by $2 \%$ glutaraldehyde- $2 \%$ paraformaldehyde in $0.1 \mathrm{M}$ phosphate buffer ( $\mathrm{pH}$. 7.4). The vomeronasal organs were removed and kept in the same fixative for 24 $\mathrm{hr}$ at $4^{\circ} \mathrm{C}$. They were cut into sections of approximately 1.0 $\mathrm{mm}$ thickness with a razor blade and postfixed in $1 \%$ osmium tetroxide in $0.1 \mathrm{M}$ phosphate buffer, dehydrated in ethanol and embedded in plastic resin (Quetol 812). Ultrathin sections were cut with a microtome (MT 7000, MRC). After being stained with uranyl acetate and lead citrate, the sections were examined under an electron microscope (JEOL, model 1200EXII).

Immunocytochemistry and lectin histochemistry: Three animals for each of the five postoperative recovery times were selected for NCAM immunocytochemical and lectin histochemical examination. The animals $(n=15)$ were deeply anesthetized with pentobarbital and perfused with $0.9 \%$ saline and $4 \%$ paraformaldehyde in $0.1 \mathrm{M}$ phosphate buffer (pH. 7.4). The vomeronasal organs were removed and kept in fixative for $24 \mathrm{hr}$ at $4{ }^{\circ} \mathrm{C}$. They were then cut into $30 \mu \mathrm{m}$ thick sections in a cryostat (JUNG GM3000, Leica), and the sections were mounted on gelatin-coated slides. For NCAM immunocytochemistry, the sections were incubated with anti-NCAM antibody (Sigma, St. Louis, Mo., U.S.A.) diluted at $1: 100$ for $1 \mathrm{hr}$ at $37^{\circ} \mathrm{C}$. After being washed in PBS for $30 \mathrm{~min}$, the sections were incubated with anti-mouse Ig biotinylated antibody diluted at 1:200 for $1 \mathrm{hr}$ at $37^{\circ} \mathrm{C}$, washed in PBS for $30 \mathrm{~min}$, and incubated with streptavidin labeled with fluorescent dye. For lectin histochemistry, the sections were first incubated in $0.3 \%$ Triton- $X$ in $0.1 \mathrm{M}$ phosphate-buffered saline (PBS) for $10 \mathrm{~min}$, and then incubated with BSL-I or VVA conjugated with FITC (Sigma, St. Louis, Mo., U.S.A.) at a concentration of $5 \mathrm{mg} / \mathrm{m} l$ for $1 \mathrm{hr}$ at $37^{\circ} \mathrm{C}$. After the final incubation, sections for both lectin histochemistry and NCAM immunocytochemistry were washed in PBS for $30 \mathrm{~min}$, coverslipped with a water-based mountant (PermaFlour, LIPSHAW), and examined under a fluorescence microscope (Axiophot, Zeiss).

\section{RESULTS}

Electron-microscopic study: Electron-microscopic examination was performed for both control sections of the vomeronasal organ (right VNO) and sections representing different stages of recovery following nerve transection (left VNO). In the control sections, the receptor cells were observed to be covered with thin microvilli. Close to the base, the receptor cell microvilli were thick, but at a short distance from the cell surface they became tapered and thin. In contrast, supporting cells had uniformly thick microvilli. Numerous receptor and supporting cell microvilli were observed to cover the luminal 

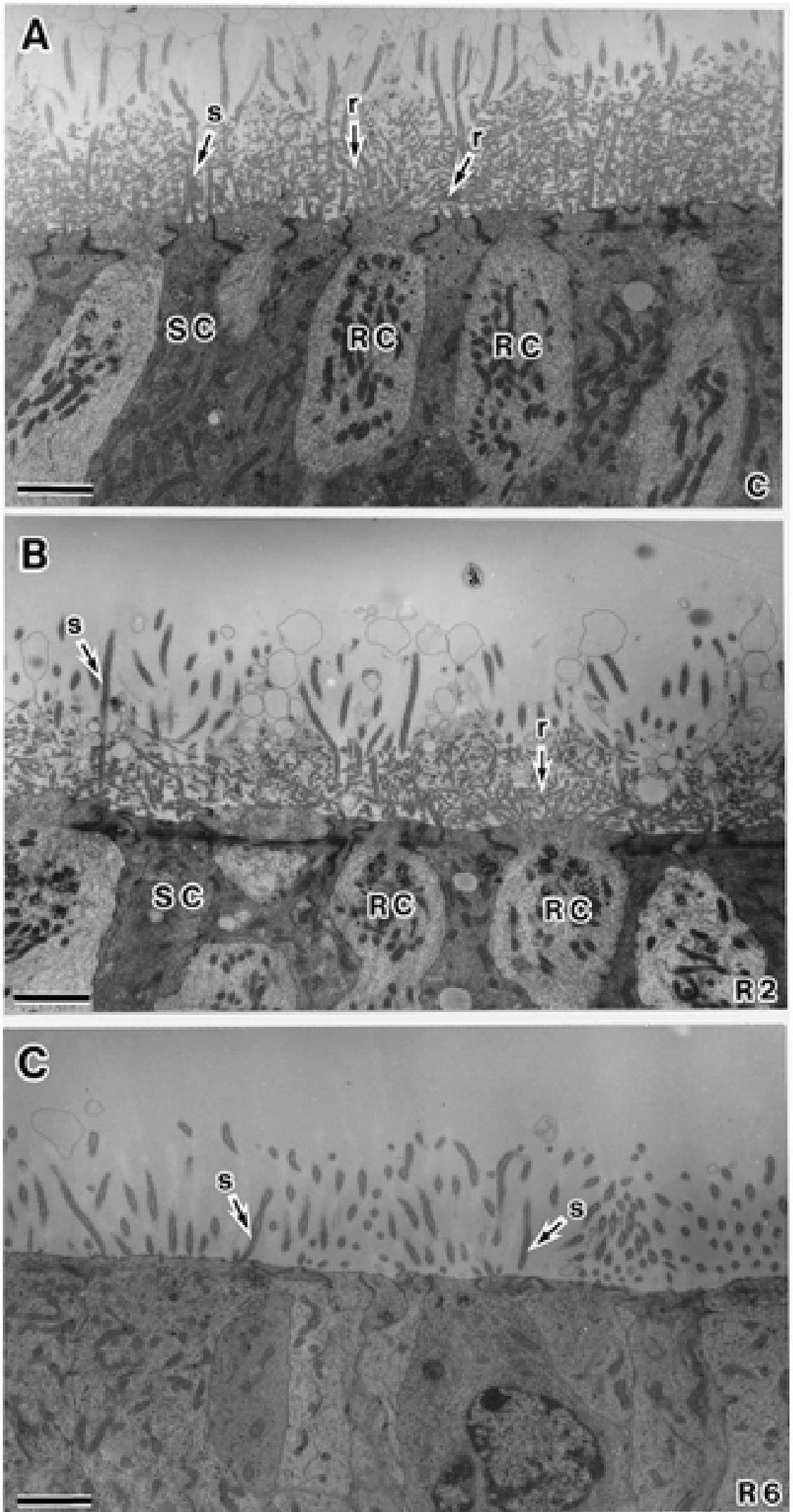

Fig. 1. Changes in the vomeronasal epithelium during degeneration of receptor cells. A. Normal morphology of the epithelial surface illustrating the microvilli on the two types of cells. Receptor cell microvilli (r) are thin and tapered while the supporting cell microvilli (s) are thicker and more uniform in diameter. B. Two days (R2) after nerve transection there was a decrease in the length and number of receptor cell microvilli. C. By day 6 (R6), most receptor cells had degenerated and none of the thin-type of microvilli were present. Only thick microvilli covering supporting cells were observed on day 6. (RC) receptor cell, (SC) supporting cell. Scale Bar: 1 $\mu \mathrm{m}$. 

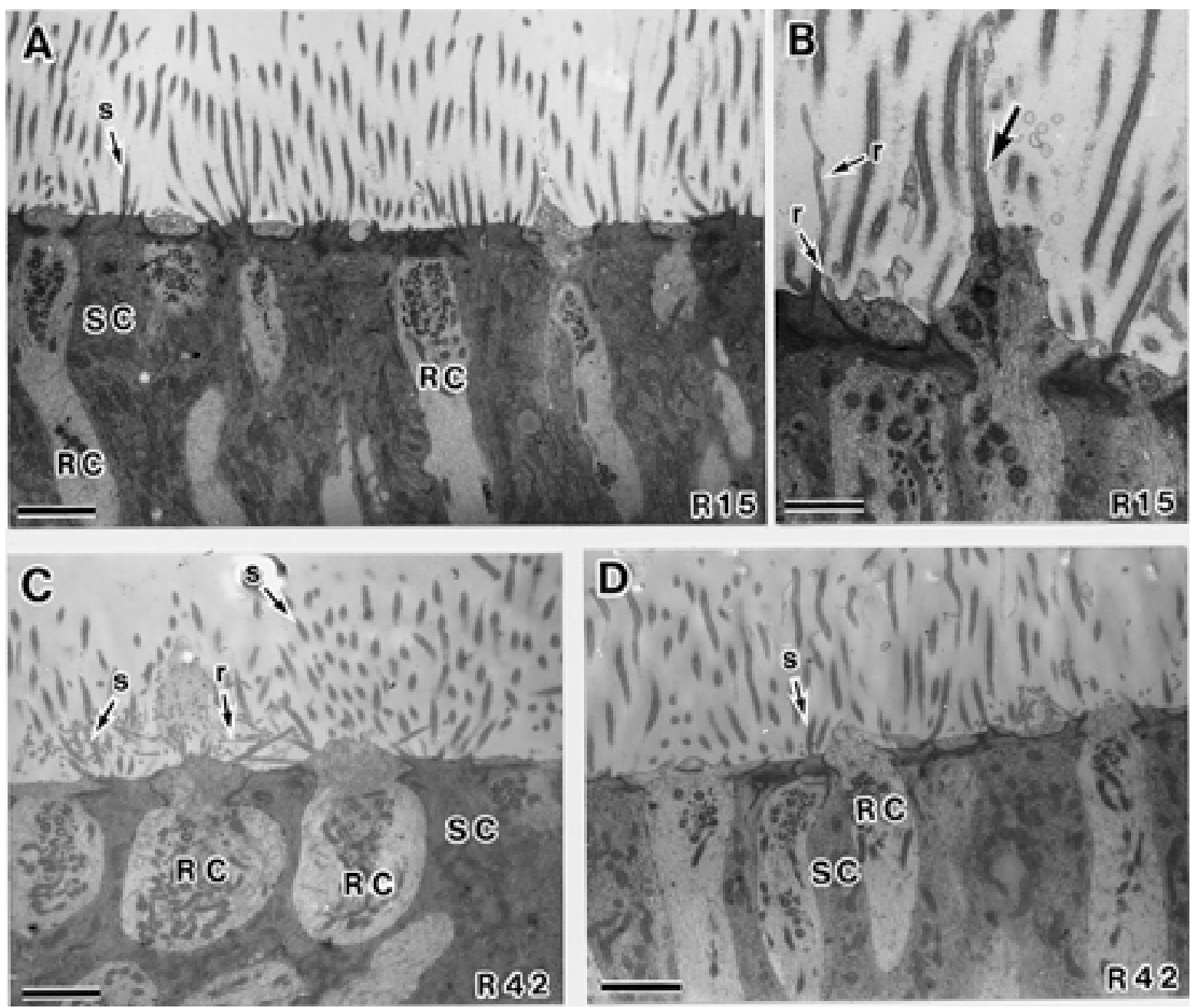

Fig. 2. Changes in the vomeronasal epithelium during regeneration of receptor cells. A. At 15 days (R15) of recovery, newly regenerated receptor cells were found in the epithelium. B. Thin microvilli and in some cases, well-defined cilia (large arrow) were observed on the surface of the receptor cells. Centrioles were also seen in the apical region of the receptor cells. At longer recovery times (R42), the sensory epithelium in some animals recovered well (C) whereas in others the regeneration was incomplete (D). (RC) receptor cell, (SC) supporting cell, (r) receptor cell microvilli, (s) supporting cell microvilli. Scale Bars: $2 \mu \mathrm{m}(\mathrm{A}, \mathrm{C}, \mathrm{D}), 1 \mu \mathrm{m}(\mathrm{B})$.

surface of the cells in control sections (Fig. 1A). By day 2 after the nerve transection, a decrease in the density of the microvilli covering the receptor cells was observed on the luminal surface of the epithelium. There were no signs of degeneration of the cytoplasm at this stage (Fig. 1B). By day 6 , the microvilli could no longer be seen covering receptor cells. Only the supporting cell microvilli were present on the surface of the epithelium at this stage (Fig. 1C) and it was difficult to discriminate between supporting cells and regenerating receptor cells. Intercellular gaps between cells were also observed in the epithelium (data not shown). On day 10, the microvilli covering the supporting cells were still observed on the surface of the epithelium. Although the receptor cell microvilli could not be observed, bud-like structures were seen protruding into the lumen from the dendritic endings of a few receptor cells and these structures also contained centrioles (data not shown). By day 15, the number of receptor cells was increased compared with that on day 10 (Fig. 2A). A few developing microvilli were identified covering the luminal surface of the receptor cells (Fig. 2B) and numerous centrioles were observed below the cell surface (Fig. 2A). Well-developed vomeronasal axon bundles were also observed in the lamina propria region (not shown in the figures), and cilia characteristic of developing receptor cells (large arrow in Fig. 2B) were observed on the surface of a few cells. On day 42 , there was considerable variability in the degree of regeneration observed in the sensory epithelium (Figs. 2C, 2D). In some animals (Fig. 2C), the receptor cell microvilli showed good recovery, whereas in others (Fig. 2D) receptor cell microvilli were still few in number.

Immunocytochemistry: In control sections of the vomeronasal epithelium, strong NCAM immunoreactivity was observed at the luminal surface and no immunoreactivity within the cell body layer (Fig. 3A). Two days following the 

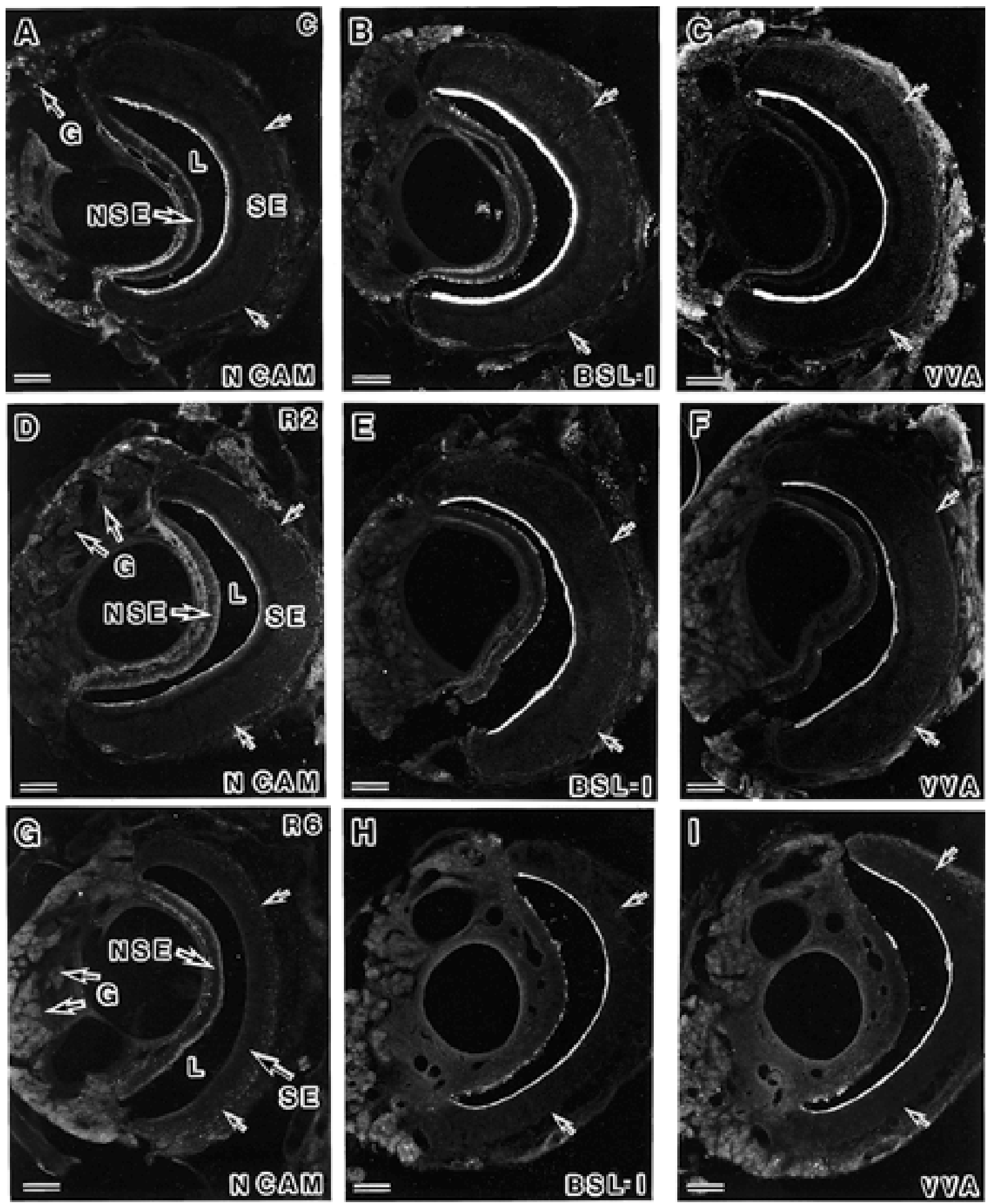

Fig. 3. Changes in NCAM, BSL-I and VVA reactivity during degeneration. Panels A, D and G show the decrease in NCAM immunoreactivity in the vomeronasal organ during receptor cell degeneration. On day 2 (R2), a slight decrease in NCAM immunoreactivity was observed and by day 6 (R6) NCAM immunoreactivity was no longer present in the sensory epithelium. Reactivity for the two lectins, BSL-I (panel B,E,H) and VVA (panel C, F, I) was decreased on the luminal surface during degeneration, with only a small residual reactivity observed on day 6 . Arrows indicate the basement membrane of the sensory epithelium. (G) vomeronasal gland, (L) lumen, (NSE) nonsensory epithelium, (SE) sensory epithelium. Scale bar: $100 \mu \mathrm{m}$. 

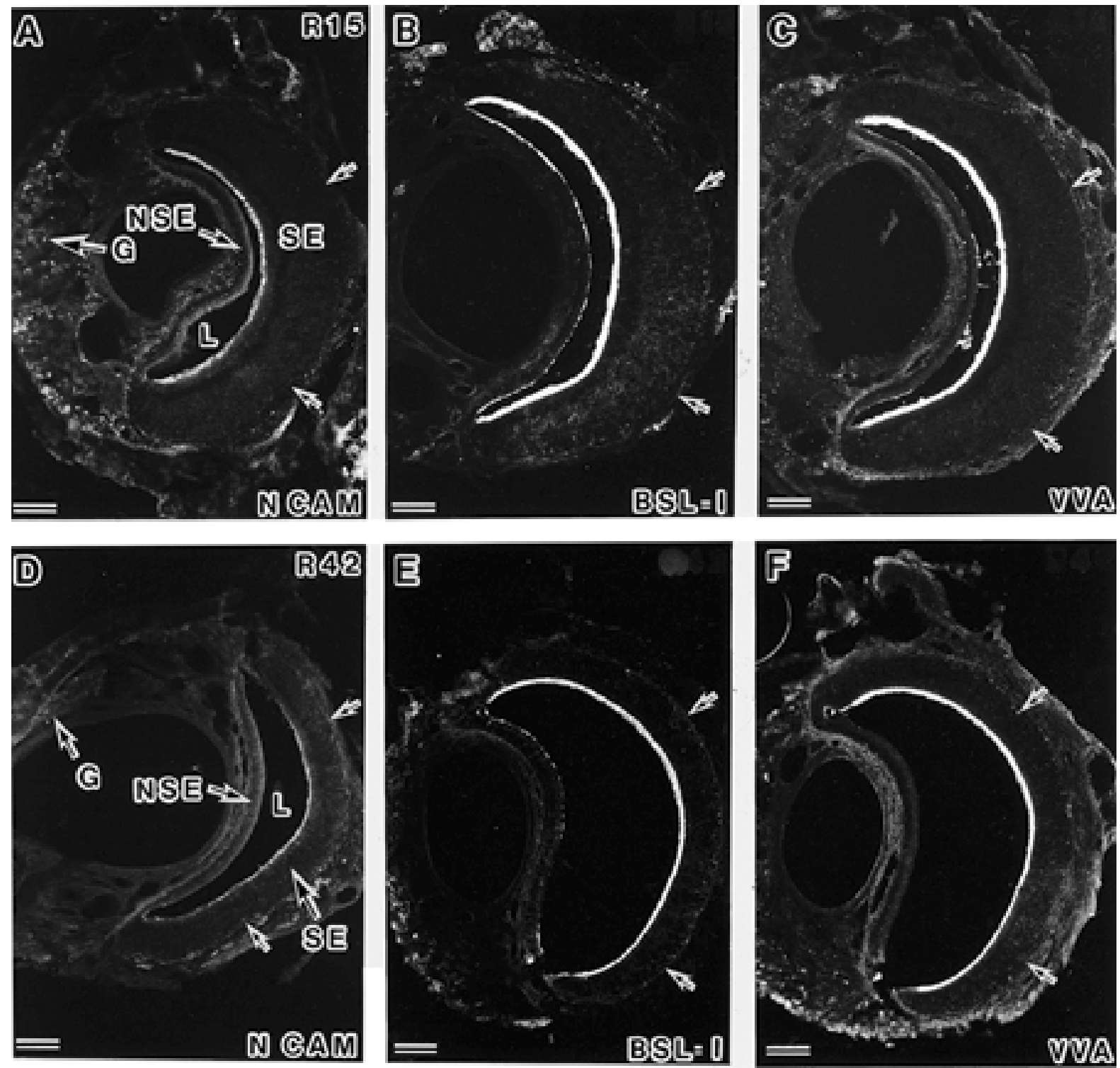

Fig. 4. Changes in NCAM, BSL-I and VVA reactivity during regeneration. Panels A and D illustrate the recovery of NCAM immunoreactivity during regeneration of receptor cells. On day 15 (R15), NCAM immunoreactivity recovered to levels similar to that observed in control sections. On day 42 (R42), the intensity was decreased to below control levels. The reactivity for BSL-I (panel B, E) and VVA (panel C, F) was increased on day 15 (R15) and decreased slightly on day 42 (R42). Arrows indicate the basement membrane. (G) vomeronasal gland, (L) lumen, (NSE) nonsensory epithelium, (SE) sensory epithelium. Scale bar: $100 \mu \mathrm{m}$.

nerve transection, NCAM reactivity could still be observed on the luminal surface of the epithelium, but it was weaker than in controls (Fig. 3D). By day 6, no NCAM immunoreactivity could be detected either on the luminal surface or in the cell body layer (Fig. 3G). However by day 15, strong NCAM immunoreactivity reappeared on the luminal surface (Fig. 4A). NCAM immunoreactivity was also observed on day 42, the longest regeneration time, however, its intensity was lower than that in controls (Fig. 4D). The nonsensory epithelium and vomeronasal glands did not show any NCAM immunoreactivity.
Lectin histochemistry: In control sections, BSL-I and VVA were observed to be bound to the luminal surface and in the cell body layer of the sensory epithelium (Figs. 3B, 3C). Reactivity for BSL-I and VVA was very intense at the luminal surface. Reactivity for these two lectins was also observed in the vomeronasal glands. Although lectin reactivity was also observed on the luminal surface of the nonsensory epithelium, it was less intense and showed a more punctate pattern. On days 2 and 6 , the reactivity for BSL-I and VVA on the luminal surface was much weaker than that in controls (Figs. 3E, 3F, 3H, 3I). Weak reactivity was also 
Table 1. Intensity of labeling at different stages after nerve transection

\begin{tabular}{lccccccc}
\hline & Control & DAY 2 & DAY 6 & DAY 10 & DAY 15 & DAY 21 & DAY 42 \\
\hline NCAM & ++ & + & - & + & ++ & ++ & + \\
BSL-I & +++ & + & + & $+l++$ & +++ & +++ & +++ \\
VVA & +++ & + & + & $+/++$ & +++ & +++ & +++ \\
\hline- ; No reaction. & & & & & & & \\
+ + Weak reaction. \\
++ ; Moderate reaction. \\
+++ ; Strong reaction.
\end{tabular}

observed in the vomeronasal glands and sensory epithelium. By day 15, the luminal surface once again showed a strong reactivity for BSL-I and VVA (Figs. 4B, 4C). Lectin reactivity in the cell body layer and vomeronasal glands returned to control levels and remained relatively constant throughout the regeneration period up to day 42 (Figs. 4E, 4F). The changes in NCAM and lectin reactivity observed during degeneration and regeneration of the vomeronasal epithelium are summarized in Table 1.

\section{DISCUSSION}

In this study, we examined the changes in the vomeronasal epithelium during degeneration and regeneration following nerve transection. Maximum degeneration of vomeronasal receptor cells following deafferentation was reported to occur on day 6 in hamsters [13], day 8 in mice [3] and at two weeks in garter snakes [32]. In this study, we found that the number of microvilli in the vomeronasal epithelium of the rat gradually decreased after nerve transection and by day 6 the microvilli could no longer be observed on receptor cells. These results confirm that degeneration of the vomeronasal receptor cells occurs within one week following nerve transection in rodents. During the early stages of regeneration (day 10-15), centrioles and bud-like structure were also observed in the dendritic endings of regenerating receptor cells. During normal development of the vomeronasal organ, buds without microvilli and centrioles have also been reported in the maturing sensory epithelium $[6,16]$. We also observed cilia on the surface of the regenerating receptor cells. Prior to this study, cilia had been seen on vomeronasal receptor cells only in immature animals and never in the adult $[6,16]$. Our observations suggest that the stages of regeneration of the vomeronasal receptor cells may be similar to those during development. The structural changes in the regenerating receptor cells appear to be similar to those observed during development. On day 42 regeneration observed in the sensory epithelium appeared to be somewhat variable. In some animals, a significant number of microvilli observed on the surfaces of the receptor cells, while in others there were only a few microvilli. Osada et al. [23] reported that the turnover period of VNO receptor cells in culture is about two weeks. The variability in cell turnover may be due to several factors, including the ability or failure of axons to reestablish connections with their target cells. It is likely that some of the variability observed in epithelial recovery on day
42 is due to the failure of some regenerated receptor cells to survive. Other factors such as variability in the distribution of stem cells and regulatory growth factors could also account for the observed differences in regeneration stages.

NCAM, which is expressed in most of immature and mature neurons [17], was selected as a marker for sensory neurons. On day 6 after nerve transection, when the microvilli could no longer be observed on vomeronasal receptor cells, NCAM immunoreactivity could also no longer be observed in the vomeronasal organ. NCAM immunoreactivity reappeared on day 15 in the vomeronasal organ. Ichikawa et al. [13] showed that the receptor cell number increased and reached its maximum by day 15 . These results demonstrate that vomeronasal nerve transection leads to a degeneration of mature vomeronasal receptor cells by day 6 , and during the subsequent recovery there is a regeneration and replacement of receptors with new cells.

Lectins were used as markers to identify vomeronasal receptor cells. BSL-I and VVA, have been shown to have a high affinity for the vomeronasal system, especially for the vomeronasal receptor cells in the sensory epithelium [31] and their axon terminals in the accessory olfactory bulb [11, 30]. Ichikawa et al. [12] studied the changes in BSL-I and VVA reactivity in the accessory olfactory bulb and found that the reactivity for both lectins gradually increased during development. During the degeneration period observed in this study, BSL-I and VVA reactivity decreased to below control levels, however, some reactivity was still present even on day 6 , when the microvilli could no longer be observed on the surfaces of the receptor cells. These findings suggest that BSL-I and VVA lectins bind not only to the receptor cells but also to supporting cells. Electron-microscopic observations confirmed the presence of BSL-I and VVA reactivity on the apical regions of both receptor and supporting cells (Yoshida-Matsuoka, unpublished data). After day 6, the reactivity for both BSL-I and VVA increased in intensity and was restored to control levels by day 15 . This increase in intensity is most likely attributable to the regeneration of the receptor cells.

It has been suggested that the recovery of the receptor cell population in the olfactory and vomeronasal systems consists of four phases. In the first phase, the organ undergoes neurogenesis and new receptor cells are produced in response to the degeneration of injured cells. The second phase consists of the development and growth of new receptor cell processes. In the third phase, cells reestablish connections with 
their targets in the olfactory bulb, and in the final phase, sensory function is restored. In the olfactory system, studies using BrdU injection following olfactory nerve axotomy have confirmed that newly dividing cells are present in the olfactory epithelium during recovery $[20,28]$. Other studies using ${ }^{3} \mathrm{H}$-thymidine labeling demonstrated an increase in the number of regenerated cells following olfactory bulbectomy $[4,25]$. The reconnection of newly formed olfactory axons to the olfactory bulb have been examined using horseradish peroxidase (HRP) in hamsters [19, 35] and rats [1]. Functional recovery in the olfactory system has been demonstrated in several species. Koster and Costanzo [15] reported that during recovery from nerve transection, hamsters first responded to electrical stimuli on day 20. Yee and Costanzo [35] showed that animals were able to detect and discriminate between odors by day 40 following bilateral olfactory nerve transection. Hendricks et al. [10] showed that olfactory neurons reestablished contact with the forebrain after bilateral bulbectomy in neonatal animals that functionally recovery in 6 weeks. Oley et al. [21] reported that the olfactory system in the pigeon was able to respond to odor stimuli after recovery from nerve transection. Pigeons were able to discriminate odorized and clean air within 16-82 days after nerve transection. All these findings are consistent with the four proposed phases of recovery, and suggest that the olfactory system has a remarkable capacity for recovery from injury.

In contrast to the histochemical, immunocytochemical, electron microscopic, and behavioral studies of regeneration in the olfactory system, studies of the vomeronasal system have been limited to morphological observations during regeneration [2, 3, 13, 29, 32-34]. In the present study, we examined the degeneration and the regeneration of the vomeronasal epithelium using both histochemical and immunocytochemical methods. We also used electron microscopy to examine detailed changes at the epithelial surface. This is the first report that compares the ultrastructural changes in the vomeronasal epithelium with histochemical and immunocytochemical changes during different stages of degeneration and regeneration. The time course of receptor cell degeneration and regeneration was consistent with that reported in previous morphological studies. In addition, findings suggest that the early stages of receptor cell regeneration in the vomeronasal epithelium are similar to those observed during development of an animal. Further studies are needed to determine if the mechanisms of cell differentiation in a developing animal are repeated during the regeneration of vomeronasal receptor cells after nerve transection.

ACKNOWLEDGMENTS. This work was supported in part by Grants-in-Aid for scientific research, 07304055 and 08640852, from the Ministry of Education, Science, Sports and Culture of Japan and by CREST of Japan Science and Technology Corporation, and a research grant, DC00165, from the National Institute on Deafness and Other Communication Disorders.

\section{REFERENCES}

1. Anders, J.J. and Hurlock, J.A. 1996. Transplanted glial scar impedes olfactory bulb reinnervation. Exp. Neurol. 142: 144150.

2. Barber, P.C. 1981. Regeneration of vomeronasal nerves into the main olfactory bulb in the mouse. Brain Res. 216: 239-251.

3. Barber, P.C. and Raisman, G. 1978. Replacement of receptor neurons after section of the vomeronasal nerves in the adult mouse. Brain Res. 147: 297-313.

4. Carr, V.M. and Farbman, A.I. 1993. The dynamics of cell death in the olfactory epithelium. Exp. Neurol. 124: 308-314.

5. Costanzo, R.M. and Graziadei, P.P.C. 1983. A quantitative analysis of changes in the olfactory epithelium following bulbectomy in hamster. J. Comp. Neurol. 215: 370-381.

6. Garrosa, M., Iñiguez, C., Fernandez, J.M. and Gayoso, M.J. 1992. Developmental stages of the vomeronasal organ in the rat: a light and electron microscopic study J. Hirnforsch. 33: 123132.

7. Graziadei, P.P.C. 1973. Cell dynamics in the olfactory mucosa. Tissue Cell. 5: 113-131.

8. Graziadei, P.P.C. and Monti Graziadei, G.A. 1978. The olfactory system: a model for the study of neurogenesis and axon regeneration in mammals. pp. 131-153. In: Neuronal Plasticity (Cotman, C.W. ed.), Raven Press, New York.

9. Graziadei, P.P.C., Levine, R.R., Giuseppina, A. and Monti Graziadei, G.A. 1979. Plasticity of connections of the olfactory sensory neuron: regeneration into the forebrain following bulbectomy in the neonatal mouse. Neuroscience 4: 713-727.

10. Hendricks, K.R., Kott, J.N., Lee, M.E., Gooden, M.D., Evers, S.M. and Westrum, L.E. 1994. Recovery of olfactory behavior. I. Recovery after a complete olfactory bulb lesion correlates with patterns of olfactory nerve penetration. Brain Res. 648: 121-133.

11. Ichikawa, M., Osada, T. and Ikai, A. 1992. Bandeiraea simplicifolia lectin I and Vicia villosa agglutinin bind specifically to the vomeronasal axons in the accessory olfactory bulb of the rat. Neurosci. Res. 13: 73-79.

12. Ichikawa, M., Takami, S., Osada, T. and Graziadei, P.P.C. 1994. Differential development of binding sites of two lectins in the vomeronasal axons of the rat accessory olfactory bulb. Brain Res. Dev. Brain Res. 78: 1-9.

13. Ichikawa, M., Osada, T. and Costanzo, R.M. 1998. Replacement of receptor cells in the hamster vomeronasal epithelium after nerve transection. Chem. Senses 23: 171-179.

14. Jia, C.P. and Halpern, M. 1996. Subclasses of vomeronasal receptor neurons: Differential expression of G proteins (Gio2 and Goo) and segregated projections to the accessory olfactory bulb. Brain Res. 719: 117-128.

15. Koster, N.L. and Costanzo, R.M. 1996. Electrophysiological characterization of the olfactory bulb during recovery from sensory deafferentation. Brain Res. 724: 117-120.

16. Mendoza, A.S. and Szabó, K. 1988. Developmental studies on the rat vomeronasal organ: vascular pattern and neuroepithelial differentiation. II. Electron microscopy. Brain Res. 467: 259268.

17. Miragall, F., Kadmon, G., Husmann, M. and Schachner, M. 1988. Expression of cell adhesion molecules in the olfactory system of the adult mouse: presence of the embryonic form of N-CAM. Dev. Biol. 129: 516-531.

18. Monti Graziadei, G.A. and Graziadei, P.P.C. 1979. Neurogenesis and neuron regeneration in the olfactory system of mammals. II. Degeneration and reconstitution of the olfactory 
sensory neurons after axotomy. J. Neurocytol. 8: 197-213.

19. Morrison, E.E. and Costanzo, R.M. 1995. Regeneration of olfactory sensory neurons and reconnection in the aging hamster central nervous system. Neurosci. Lett. 198: 213-217.

20. Nakamura, H. 1991. Immunohistochemical observations of dividing cells in olfactory epithelium using anti-BrdU antibody. Eur. Arch. Otorhinolaryngol. 248: 298-301.

21. Oley N., DeHan, R.S., Tucker, D., Smith, J.C. and Graziadei, P.P.C. 1975. Recovery of structure and function following transection of the primary olfactory nerves in pigeons. J. Comp. Physiol. Psychol. 88: 477-495.

22. Onoda, N. 1988. Monoclonal antibody immunohistochemistry of degenerative and renewal patterns in rabbit olfactory receptor neurons following unilateral olfactory bulbectomy. Neuroscience 26: 1013-1022.

23. Osada, T., Ikai, A., Costanzo, R.M., Matsuoka, M. and Ichikawa, M. 1999. Continual neurogenesis of vomeronasal neurons in vitro. J. Neurobiol. 40: 226-233.

24. Roskams, A.J.I., Bethel, M.A., Hurt, K.J. and Ronnett, G.V. 1996. Sequential expression of Trks A, B, and C in the regenerating olfactory neuroepithelium. J. Neurosci. 16: 1294-1307.

25. Schwartz, L.M., Chikaraishi, D.M. and Kauer, J.S. 1991. Characterization of potential precursor populations in the mouse olfactory epithelium using immunocytochemistry and autoradiography. J. Neurosci. 11: 3556-3564.

26. Schwob, J.E., Youngentob, S.L. and Mezza, R.C. 1995. Reconstitution of the rat olfactory epithelium after methyl bromideinduced lesion. J. Comp. Neurol. 359: 15-37.

27. Shapiro, L.S., EE, P.L. and Halpern, M. 1995. Lectin histochemical identification of carbohydrate moieties in opossum chemosensory systems during development, with special emphasis on VVA-identified subdivisions in the accessory olfactory bulb. J. Morphol. 224: 331-349.

28. Suzuki, Y. and Takeda, M. 1991. Basal cells in the mouse olfactory epithelium after axotomy: immunohistochemical and electron-microscopic studies. Cell Tissue Res. 266: 239-245.

29. Suzuki, Y., Takeda, M., Obara, N. and Suzuki, N. 1998. Colchicine-induced cell death and proliferation in the olfactory epithelium and vomeronasal organ of the mouse. Anat. Embryol. 198: 43-51.

30. Takami, S., Graziadei, P.P.C. and Ichikawa, M. 1992. The differential staining patterns of two lectins in the accessory olfactory bulb of the rat. Brain Res. 598: 337-342.

31. Takami, S., Getchell, M.L. and Getchell, T.V. 1994. Lectin histochemical localization of galactose, $\mathrm{N}$-acetylgalactosamine, and $\mathrm{N}$-acetylglucosamine in glycoconjugates of the rat vomeronasal organ, with comparison to the olfactory and septal mucosae. Cell Tissue Res. 277: 211-230.

32. Wang, R.T. and Halpern, M. 1982a. Neurogenesis in the vomeronasal epithelium of adult garter snakes. 1. Degeneration of bipolar neurons and proliferation of undifferentiated cells following experimental vomeronasal axotomy. Brain Res. 237: 23-39.

33. Wang, R.T. and Halpern, M. 1982b. Neurogenesis in the vomeronasal epithelium of adult garter snakes. 2. Reconstitution of the bipolar neuron layer following experimental vomeronasal axotomy. Brain Res. 237: 41-59.

34. Wang, R.T. and Halpern, M. 1988. Neurogenesis in the vomeronasal epithelium of adult garter snakes: 3 . Use of ${ }^{3} \mathrm{H}$-thymidine autoradiography to trace the genesis and migration of bipolar neurons. Am. J. Anat. 183: 178-185.

35. Yee, K.K. and Costanzo, R.M. 1995. Restoration of olfactory mediated behavior after olfactory bulb deafferentation. Physiol. behav. 58: 959-968. 